\title{
Design of permanent magnet brushless motors with asymmetric air gap for electric vehicles
}

\author{
K. T. Chau ${ }^{\mathrm{a})}$ \\ Department of Electrical and Electronic Engineering, The University of Hong Kong, Pok Fu Lam Road, \\ Hong Kong, China \\ Wei Cui and J. Z. Jiang \\ Department of Automation, Shanghai University, Shanghai 200072, China

\begin{abstract}
Zheng Wang
Department of Electrical and Electronic Engineering, The University of Hong Kong, Pok Fu Lam Road, Hong Kong, China
\end{abstract}

(Presented on 3 November 2005; published online 25 April 2006)

\begin{abstract}
This paper proposes a cost-effective approach to design permanent magnet brushless dc motors for electric vehicles. The key is to shape the pole arc in such a way that the air gap length is at a maximum at the leading edge of each rotor pole arc and at a minimum at the trailing edge of the same pole arc, hence resulting in an asymmetric air gap. Thus, for a specified rotational direction, the distortion of air gap flux density and hence the torque ripple can be significantly suppressed. Also, with the use of advanced conduction angle control, the motor can achieve a wide speed range. The proposed motor drive is designed and implemented for a low-voltage battery-powered electric motorcycle. (ㅇ 2006 American Institute of Physics. [DOI: 10.1063/1.2173615]
\end{abstract}

\section{INTRODUCTION}

The development of permanent magnet (PM) brushless motors has accelerated with the invention of neodymiumiron-boron (Nd-Fe-B) magnets. ${ }^{1}$ There are two major types, namely, the PM brushless ac (PMBac) motor ${ }^{2}$ and the PM brushless dc (PMBdc) motor. ${ }^{3}$ For electric vehicle (EV) propulsion, the corresponding motor needs to offer high efficiency, high power density, smooth torque, and a wide speed range. The PMBdc motor inherently offers the advantages of high efficiency and high power density. However, it suffers from the problems of high torque ripples and limited constant-power speed range.,

The problem of high torque ripples is mainly due to the effect of high armature reaction. To reduce this armature reaction, the rotor needs to be specially laminated or incorporated with a special air slot to increase the reluctance of the armature flux path. ${ }^{5}$ In this paper, rather than adopting complicated rotor structures, a different design approach will be proposed. This approach can effectively suppress the armature reaction, and hence, the torque ripple of the PMBdc motor. As it is different from the PMBac motor, the PMBdc motor cannot utilize coordinate transformation to perform flux weakening control for constant-power operation. Thus, advanced conduction angle control will be adopted to significantly widen the constant-power speed range of the proposed motor. Finally, the motor will be applied to a low-voltage battery-powered electric motorcycle.

\section{DESIGN AND ANALYSIS}

The air gap length is purposely minimized so as to achieve high power density for the conventional PMBdc mo-

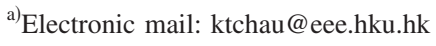

tor. However, such minimization induces the problem of armature reaction. On one hand, the armature field strengthens the air gap field at the leading edge of each rotor pole arc, hence causing magnetic saturation. On the other hand, the armature field opposes the air gap field at the trailing edge of the same pole arc, hence weakening the air gap flux density. To suppress this armature reaction while maintaining high power density, the rotor is specially shaped in such a way that the air gap length is at a maximum at the leading edge of each rotor pole arc and at a minimum at the trailing edge of the same pole arc, hence resulting in an asymmetric air gap for each rotor pole. Figure 1 shows the proposed three-phase four-pole 24-slot PMBdc motor. Its winding arrangement is shown in Fig. 2. This motor is attractive for EV propulsion since the rotation is essentially unidirectional.

As depicted in Fig. 3, when the rotor rotates in a counterclockwise direction, the air gap length at point $P$ changes from the maximum $\delta_{\max }$ to the minimum $\delta_{\min }$ within each pole period. Thus, the proposed asymmetric air gap can weaken the armature flux at the leading edge while compensating it at the trailing edge. Therefore, the distortion of air gap flux density and hence the torque ripple can be significantly suppressed. It should be noted that when the rotor rotates in a clockwise direction, the flux density distortion, and hence the torque ripple, becomes worse.

By employing finite element analysis (FEA) as shown in Fig. 4, the maximum and minimum air gap lengths are optimized to be 0.6 and $1.5 \mathrm{~mm}$, respectively. During the manufacturing process, the maximum permissible deviation is $0.05 \mathrm{~mm}$. By applying this deviation to the proposed design $(0.65-1.55 \mathrm{~mm})$, the resulting torque ripple does not have a noticeable change. Hence, based on the average air gap length of $1.05 \mathrm{~mm}$, a $5 \%$ manufacturing tolerance of the optimal air gap lengths is acceptable. 


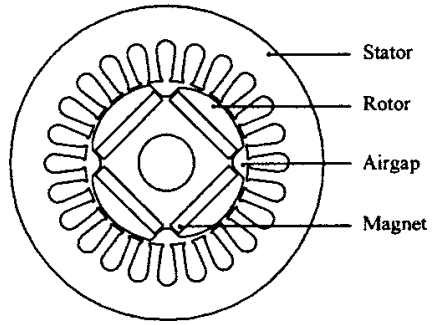

FIG. 1. Proposed motor configuration.

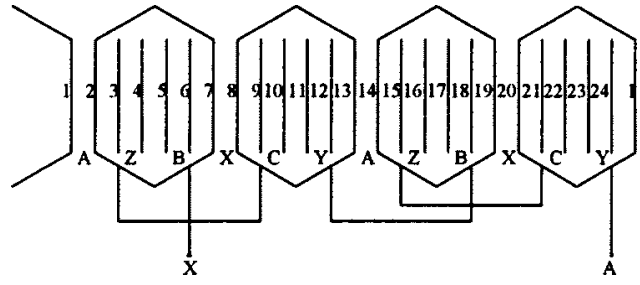

FIG. 2. Proposed winding arrangement.

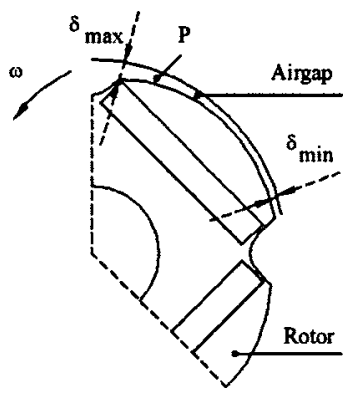

FIG. 3. Asymmetric air gap design.

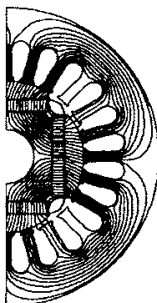

(a)

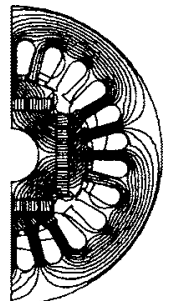

(b)
FIG. 4. Magnetic flux density distributions: (a) no load and (b) full load.

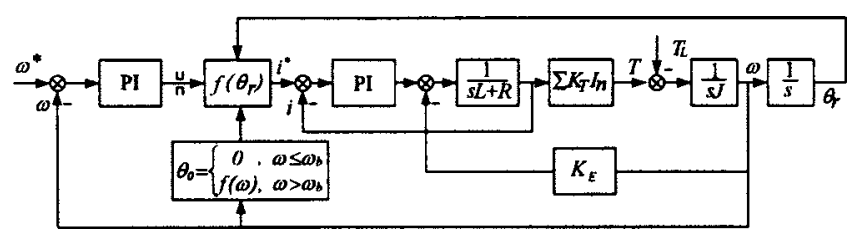

FIG. 5. Advanced conduction angle control.

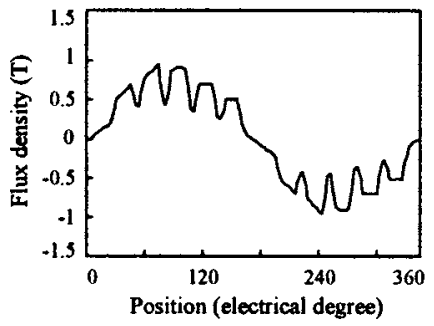

(a)

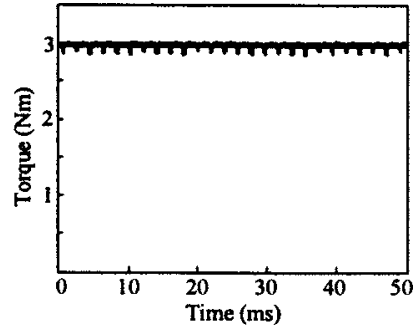

(b)
FIG. 6. Operating wave forms with asymmetric air gap under counterclockwise rotation: (a) air gap flux density and (b) torque.
TABLE I. Motor specifications and parameters.

\begin{tabular}{ll}
\hline \hline & \\
DC link voltage & $24 \mathrm{~V}$ \\
Rated phase current & $95 \mathrm{~A}$ \\
Rated motor speed & $3300 \mathrm{rpm}$ \\
Rated torque & $3 \mathrm{Nm}$ \\
Stator outer diameter & $100 \mathrm{~mm}$ \\
Stator inner diameter & $52 \mathrm{~mm}$ \\
Winding resistance & $4.70 \mathrm{~m} \Omega$ \\
$D$-axis inductance & $18.68 \mu \mathrm{H}$ \\
$Q$-axis inductance & $39.8 \mu \mathrm{H}$ \\
Maximum air gap length & $1.5 \mathrm{~mm}$ \\
Minimum air gap length & $0.6 \mathrm{~mm}$ \\
Rotor outer diameter & $50.8 \mathrm{~mm}$ \\
Rotor inner diameter & $18 \mathrm{~mm}$ \\
Magnet height & $4.0 \mathrm{~mm}$ \\
Magnet material & $\mathrm{Nd}-\mathrm{Fe}-\mathrm{B}$ \\
\hline \hline
\end{tabular}

\section{CONTROL AND OPERATION}

For EV propulsion, the motor requires a wide range of constant-power operation for cruising. Because the PM flux is uncontrollable, the PM brushless motors cannot readily offer constant-power operation. To enable the proposed PMBdc motor to achieve wide-speed constant-power operation, an advanced conduction angle (ACA) control scheme ${ }^{4}$ is to be employed. This ACA control functions to advance the conduction angle $\theta_{0}$ of the phase current $i$ with respect to the rotational emf $e$ in such a way that the corresponding transformer emf $L(d i / d t)$ can reduce $e$ for constant-power operation:

$$
u=R i+L(d i / d t)+e,
$$

where $u$ is the applied voltage, $R$ is the winding resistance, and $L$ is the winding inductance. Different from flux weakening control, the ACA control does not need to directly change $e$ and no coordinate transformation is necessary. Nevertheless, $L$ needs to be sufficiently large so that $e$ can be effectively suppressed by $L(d i / d t)$ even at high speeds.

Figure 5 shows the control block diagram. The core is the lookup table of $\theta_{0}$ in which $\theta_{0}=0^{\circ}$ is used when the motor speed $\omega$ is smaller than or equal to the base speed $\omega_{b}$, whereas $\theta_{0}=f(\omega)$ is adopted when $\omega$ is larger than $\omega_{b}$. In general, the rated speed is selected as the base speed and the function $f(\omega)$ is determined by computer simulation.

\section{SIMULATION AND EXPERIMENTATION}

Since the battery-powered electric motorcycle has been identified as the most viable type of EV for commercialization, the proposed motor is purposely designed for a $24 \mathrm{~V}$ battery-powered electric motorcycle. Table I lists its specifications and major parameters. Figures $6-8$ show the simulated air gap flux density and torque wave forms when selecting the proposed asymmetric air gap $(0.6-1.5 \mathrm{~mm})$ with counterclockwise rotation, the constant air gap $(1.1 \mathrm{~mm})$, and the same asymmetric air gap with clockwise rotation, respectively. The results agree with the theoretical prediction that the proposed design offers the least flux density distortion and minimum torque ripple, while the asymmetric design 


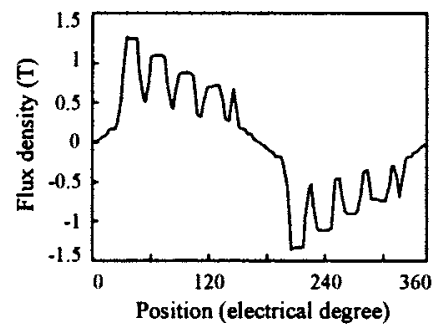

(a)

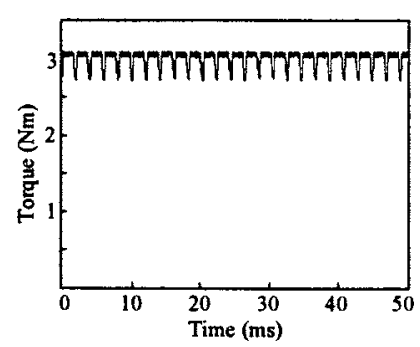

(b)
FIG. 7. Operating wave forms with constant air gap: (a) air gap flux density and (b) torque. (a)

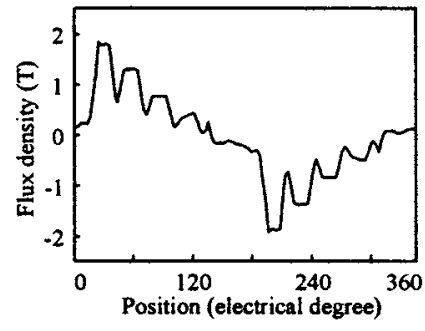

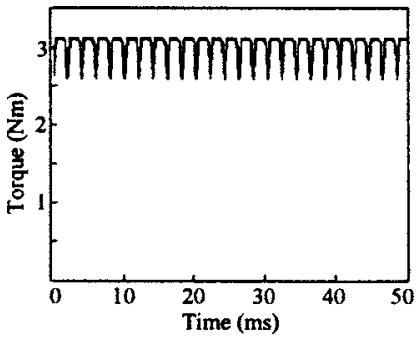

(b)
FIG. 8. Operating wave forms with asymmetric air gap under clockwise rotation: (a) air gap flux density and (b) torque.

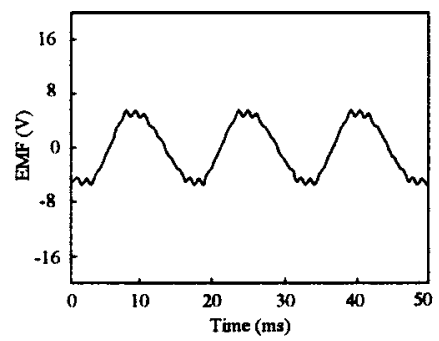

(a)

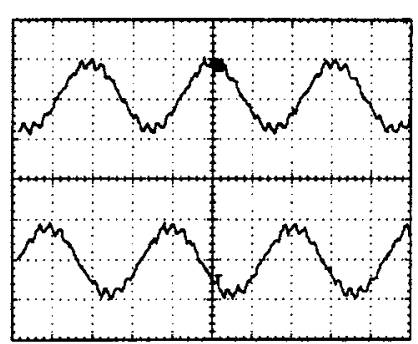

(b)
FIG. 9. Comparison of no-load emf wave forms at $2000 \mathrm{rpm}$ : (a) simulated and (b) measured (5 V/div, $5 \mathrm{~ms} / \mathrm{div})$.

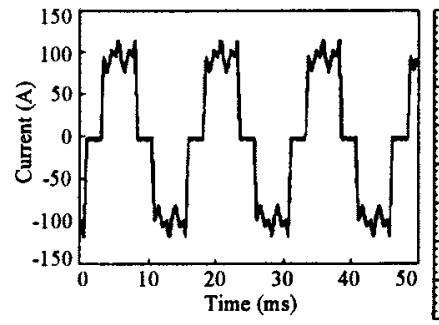

(a)

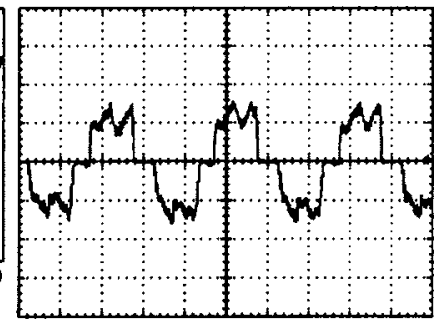

(b)
FIG. 10. Comparison of phase current wave forms at $2000 \mathrm{rpm}$ : (a) simulated and (b) measured (80 A/div, $5 \mathrm{~ms} / \mathrm{div})$.

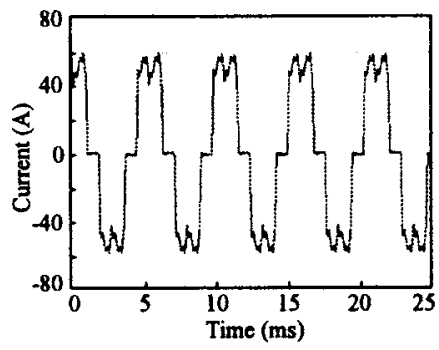

(a)

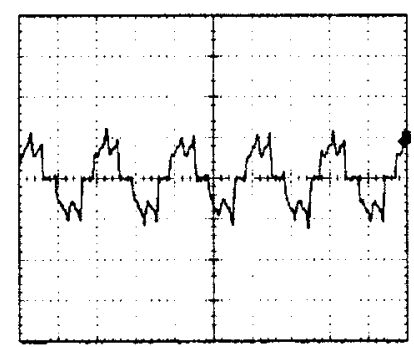

(b)
FIG. 11. Comparison of phase current wave forms at $6000 \mathrm{rpm}$ : (a) simulated and (b) measured (60 A/div, $2.5 \mathrm{~ms} / \mathrm{div})$.

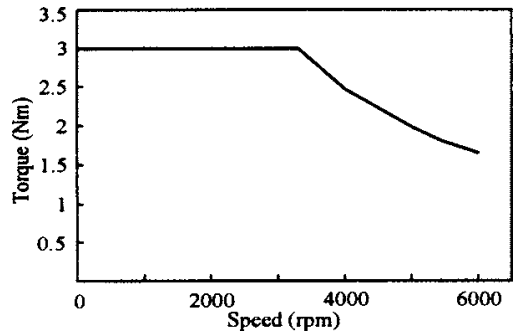

FIG. 12. Measured torque-speed capability.

with the clockwise rotation gives the worst results. Moreover, as shown in Figs. 6 and 7, the proposed asymmetric air gap design offers a torque ripple of $5 \%$ while the conventional design offers a torque ripple of $12.7 \%$, hence confirming the improvement of torque smoothness.

Figure 9 shows both the simulated and measured no-load emf wave forms at $2000 \mathrm{rpm}$. The corresponding agreement is very good with the peak value of about $5 \mathrm{~V}$. Figures 10 and 11 depict both the simulated and measured phase current wave forms for constant-torque operation at $2000 \mathrm{rpm}$ with $\theta_{0}=0^{\circ}$ and constant-power operation at $6000 \mathrm{rpm}$ with $\theta_{0}$ $=40^{\circ}$, respectively. As expected, the agreements are also very good, namely, the peak value of about $120 \mathrm{~A}$ when $\theta_{0}$ $=0^{\circ}$, and about $60 \mathrm{~A}$ when $\theta_{0}=40^{\circ}$. Finally, the measured torque-speed capability is plotted in Fig. 12, confirming that the proposed motor can offer constant-power operation from 3300 to $6000 \mathrm{rpm}$.

\section{CONCLUSIONS}

In this paper, a PMBdc motor has been designed and implemented for a low-voltage battery-powered electric motorcycle. By using the asymmetric air gap design and advanced conduction angle control, the proposed motor can offer smoother torque and wider speed range than its counterparts. Quantitatively, the torque ripple has been reduced from $12.7 \%$ to $5 \%$, while the speed range has been extended from 3300 to $6000 \mathrm{rpm}$. Theoretical discussion, computer simulation, and experimental verification have been provided for illustration.

\section{ACKNOWLEDGMENT}

This work was partially funded by a grant (HKU7035/ 01E) from the Research Grants Council, Hong Kong Special Administrative Region, China.

${ }^{1}$ T. M. Jahns, Proc. IEEE 82, 1241 (1994).

${ }^{2}$ W. Cui, K. T. Chau, J. Z. Jiang, and C. C. Chan, J. Appl. Phys. 97, 1 (2005).

${ }^{3}$ J. Gan, K. T. Chau, C. C. Chan, and J. Z. Jiang, IEEE Trans. Magn. 36, 3810 (2000).

${ }^{4}$ C. C. Chan, K. T. Chau, J. Z. Jiang, W. Xia, M. Zhu, and R. Zhang, IEEE Trans. Ind. Electron. IE-43, 331 (1996).

${ }^{5}$ C. C. Chan and K. T. Chau, IEEE Trans. Veh. Technol. 45, 180 (1996). 